\title{
Hacia una nueva concepción de la discapacidad
}

María Eugenia Caicedo**

\section{La Asociación Colombiana de Terapia Ocupacional}

Quiero agradecer a la ACTO por haberme invitado a participar en esta celebración de los 30 años de su fundación. Para quienes hemos estado vinculados a ella incluso antes de que se constituyera legalmente, es motivo de orgullo el ver los avances que se han obtenido durante este tiempo y como cada vez se ha definido mas su vocación científica como interlocutor válido que representa a los terapeutas en los asuntos que tienen que ver con nuestra profesión, asumiendo la responsabilidad histórica que ello significa para nuestro desarrollo disciplinar.

La jornada con la que se realiza esta celebración está dedicada a uno de los aspectos tradicionales del ejercicio y quizás uno de los más representativos de su identidad, lo que tradicionalmente se ha llamado la discapacidad física. Para el caso concreto de mi intervención tiene que ver con la delimitación de la discapacidad entendida como un genérico de las dificultades funcionales dentro de un grupo social dado.

Mi intervención está motivada en uno de los aspectos que más me ha inquietado durante todos estos años como es el de la ocupación humana y su significado en los aspectos de funcionalidad- disfuncionalidad, personal-social paradojas que marcan y enriquecen la esencia misma de la profesión.

\footnotetext{
* Ponencia: Seminario Avances en Terapia Ocupacional para la Rehabilitación de Personas con Discapacidad Física. A.C.T.O., Bogotá, marzo 2002.

** T.O. Universidad del Rosario. Mg. Psicología Comunitaria, Univ. Javeriana. Mg. Integración de Personas con Discapacidad, Univ. de Salamanca, España. Estudios de Maestría Universitaria, Univ. del Rosario.
} 


\section{La Ocupación para el Terapeuta Ocupacional}

Una de las cuestiones más difíciles es definir el ámbito ocupacional para dentro de ese marco establecer la funcional. La ocupación tiene un papel muy importante en el desarrollo y desempeño considerado adecuado y satisfactorio del ser humano para un rango determinado de edad y en un grupo social definido, como instrumento que mantiene y transforma una cultura y por tanto la sociedad, pero no es tan fácil definir los aspectos ocupacionales más allá de constitutivos de la vida diaria en un marco social dado.

Nuestra esencia es interdisciplinaria, el cuerpo de conocimientos propio de la profesión se agrupa alrededor de la comprensión de la ocupación cotidiana del ser humano y su aplicabilidad terapéutica tiene que ver con la forma como esos conocimientos se traducen en prácticas que contribuyen a mejorar los desempeños ocupacionales en escenarios vitales como son el cuidado personal, el aprendizaje y el trabajo y la utilización del tiempo libre. (Kielhofner, G. 1997). Esto quiere decir que toma de ciencias aparentemente tan diversas como la biología, la economía o la sicología. Como tal es imposible encontrar un estatuto único de la profesión; pretender uniformar los marcos teóricos o sus practicas lejos de acrecentar la identidad empobrece la concepción y lesiona la posibilidad de crecimiento disciplinar.

La Terapia Ocupacional se direcciona desde la Ocupación Humana es decir desde una naturaleza ocupacional, una capacidad humana para determinar y cambiar los hábitos ocupacionales así como de producir cambios en todo su ser a partir del comportamiento ocupacional (hasta aquílas afirmaciones de Keilhofner) y yo añadiría la valoración de la vida cotidiana para incidir en la orientación de nuestra propia historia, que sin duda es parte de la historia social.

Como vemos el cuerpo de conocimientos que soporta la ocupación es de naturaleza interdisciplinar e implica una aplicación tecnológica- la aplicación de un modelo teórico (que no es otra cosa que una disposición lógica determinada de los conocimientos de soporte) - y una posición ética que acompaña la aplicación de los elementos mencionados; proceso que ocurre de manera sistémica y que se trasforma en virtud de los resultados y de la evaluación sistemática. (Willard/Spackman, 1998).

El ejercicio de la Terapia Ocupacional como arte está en relación directa con la vida cotidiana de quienes requieren nuestro servicio, es decir de los que presentan 
o están en riesgo de manifestar problemas en su desempeño ocupacional o de los grupos que presentan unos estilos de vida que buscamos preservar. Para construir el producto propio de su quehacer, el profesional de la Terapia Ocupacional necesita ineludiblemente relacionarse y movilizar múltiples agentes de diversos sectores, desde la familia hasta el empresario, pasando por el vecindario; el maestro, el ingeniero y otros (Vergara, 2000). El terapeuta ocupacional sabe desde siempre que debe trabajar con el entorno como única manera de producir de manera estable los cambios que requiere en ocupación humana.

Hasta aquí hemos considerado de manera tangencial los aspectos que considero claves de la profesión para la reflexión. La Terapia Ocupacional tiene entonces un objeto de estudio complejo, la ocupación, que influye y es influida no solamente por otras disciplinas sino por los entornos donde actúa, eso quiere decir que es posible de abordarla en su concepción y aplicación tanto desde entorno hacia el individuo como desde al persona hacia su ambiente mediáto e inmediato y ambos abordajes son validos para una disciplina cuya naturaleza es personal social, en ambos casos los compromisos ético existen pero son diferentes porque varía el foco de atención.

\begin{tabular}{|l|l|}
\hline \multicolumn{2}{|c|}{ Ocupación } \\
\hline Focalizado en la persona & Focalizado en familia como célula social. \\
\hline Competencias personales & Competencias sociales \\
\hline Comportamiento ocupacional funcional & Cultura grupal \\
\hline Vida cotidiana & Cultura \\
\hline Actividad físico-psicológica & Participación \\
\hline $\begin{array}{l}\text { Responsabilidad sobre la persona } \\
\text { y su entorno inmediato. }\end{array}$ & Responsabilidad sobre población, territorio. \\
\hline
\end{tabular}

\section{Discapacidad}

El otro eje de esta charla es el concepto de la discapacidad, que según la OMS se ha concebido en la dialéctica entre el modelo medico tradicional y el modelo social, 
de acuerdo con lo cual se concibe como un problema personal directamente relacionado con limitaciones personales y que por tanto debe ser abordado desde la perspectiva individual y la intervención profesional especializada que pretende una mejor adaptación del sujeto a su condición y al medio en que se desenvuelve y el modelo social que considera el fenómeno principalmente como un problema social desde el punto de vista de la integración de estas personas a la sociedad. La discapacidad es un complicado conjunto de condiciones, muchas de las cuales se deben a la organización social. El manejo del problema es aquí responsabilidad colectiva y requiere de modificaciones ambientales para la participación plena de estas personas en todas las áreas de la sociedad.

La nueva clasificación internacional del funcionamiento de la discapacidad y de la salud (CIF), utilizando un modelo biopsicosocial se coloca entre ambas posiciones considerando tanto los factores físicos como los personales y sociales que configuran las diferentes dimensiones de la discapacidad y considera genéricamente como discapacidad la limitación derivada de este complejo de factores que influyen negativamente en el desempeño en la realidad cotidiana.

En la CIF el concepto de funcionamiento se puede considerar un término global, que hace referencia a todas las funciones corporales, actividades y participación y de manera similar el término discapacidad engloba las deficiencias, limitaciones en la actividad o restricciones en la participación, el funcionamiento y discapacidad entonces se conciben en una interacción dinámica entre los factores de salud como los contextuales tanto personales como ambientales. Es aquí donde la discapacidad y la intervención sobre esta condición se relaciona directamente con la función de la Terapia Ocupacional que como ya hemos dicho, independiente de su concepción teórica se ocupa de la realidad cotidiana de las personas y de las habilidades que tenemos y desarrollamos para cumplir con éxito las funciones que se nos atribuyen en esa cotidianidad.

La discapacidad esta siendo considerada no solamente como un problema que atañe a un porcentaje determinado de la población vulnerable que presenta una limitación claramente identificable sino como una situación que es transversal a la condición humana y a la vida, todos tenemos limitaciones en determinados momentos de nuestra vida y ante determinadas circunstancias, atañe a todos como población susceptible de discapacidad. Cuando las expectativas de vida aumentan con el consecuente riesgo de secuelas de entidades crónicas, cuando los riesgos de 


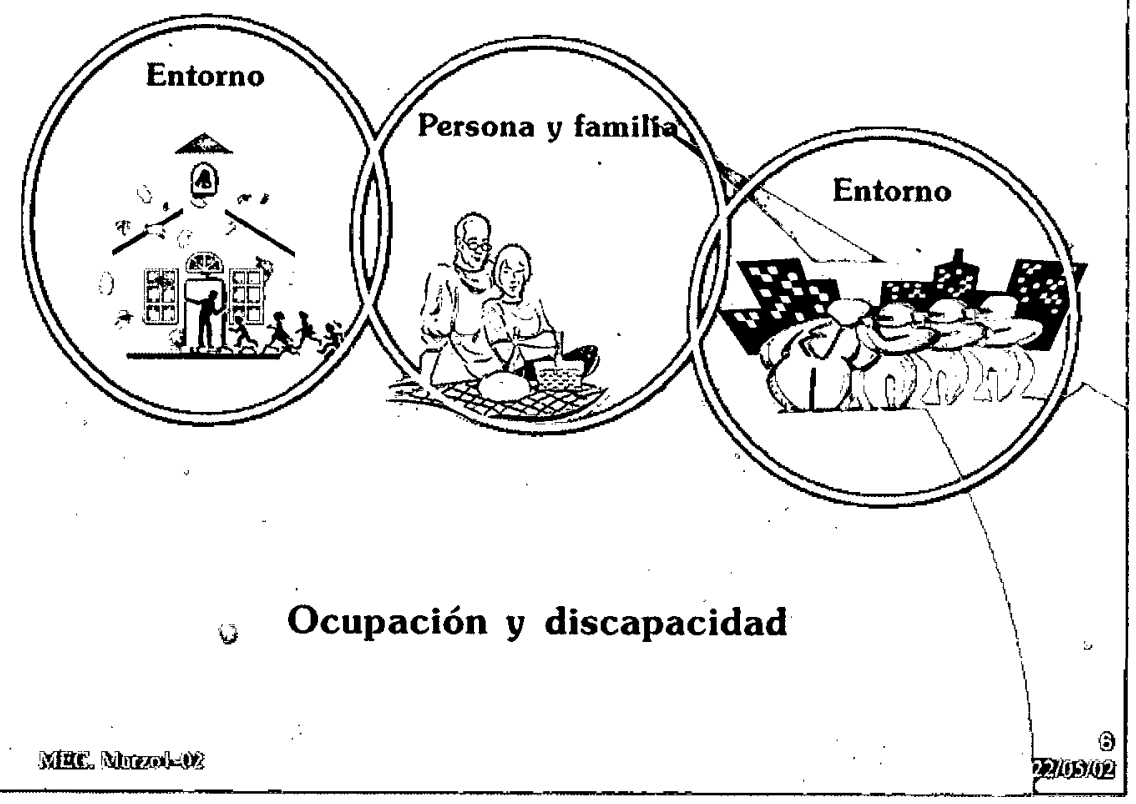

la sociedad moderna y en nuestro caso de la violencia se multiplican, hay población con discapacidad identificada, personas con discapacidad y también situación de discapacidad que hace que la problemática deje de ser un problema de un grupo marginal ( $10 \%$ a $12 \%$ de la población general para convertirse en una situación transversal a los diferentes programas que busquen mejorar la calidad de vida de la población y que ameritan la formación de una política pública de discapacidad.

\begin{tabular}{|l|l|}
\hline Desde & Hacia \\
\hline Necesidades básicas & Derechos. Capacidades \\
\hline Representación & Participación \\
\hline Individuos & Familias \\
\hline Políticas gubernamentales & Políticas públicas \\
\hline
\end{tabular}

(Continúa...) 


\begin{tabular}{|l|l|}
\hline Desde & Hacia \\
\hline Enfoque sectorial producto intersectorial & $\begin{array}{l}\text { Enfoque intersectorial, producto supre- } \\
\text { sectorial }\end{array}$ \\
\hline Evaluación de productos & Evaluación de procesos \\
\hline Asistencialismo & $\begin{array}{l}\text { Prácticas culturales para desarrollo } \\
\text { institucional }\end{array}$ \\
\hline Programación desde la oferta & Programación desde la demanda \\
\hline Verticalismo & Horizontalidad \\
\hline Centralismo & Descentralización \\
\hline Afecta grupos vulnerables & Es trasversal a la vida \\
\hline
\end{tabular}

\section{Intervención}

Respecto a la posición de los rehabilitadores en general, frente al tema de la discapacidad revisando las revistas de Ocupación Humana en búsqueda de conceptos que ya hayan sido trabajados en el país desde el punto de vista de los terapeutas ocupacionales, encuentro que Alicia Trujillo se ocupó de este tema en un articulo de 2000 donde señalaba la urgencia de que los profesionales colombianos incorporen a su ejercicio los desarrollos contemporáneos sobre la discapacidad para asegurar la supervivencia de los servicios de rehabilitación en un contexto político y social que cada vez tolerara menos la atención reduccionista, porque estos servicios solo aseguraran su sostenibilidad si abandonan el ejercicio técnico y especializado para incorporarse cada vez mas a los grandes movimientos político sociales en el campo de la discapacidad.

\section{Intervención}

- Persona con discapacidad

- La persona es el centro

- Desarrollo personal

- Responsabilidad personal

- Servicios especializados

- La limitación es lo central
- Situación de discapacidad

- Persona-entorno

- Impacto social

- Compromiso social

- Servicios que incluyen el entorno

- La capacidad es lo primordial 
No es mi intención ni el propósito de esta charla entrar a discutir aspectos técnicos de la intervención, solo quiero señalar como aquí también coexisten dos modelos de intervención claramente identificables.

\section{Un interrogante y una invitación para los terapeutas}

Si se dan estos cambios conceptuales para los rehabilitadores como personas especializadas en tratar aquellas con discapacidad qué ocurre con profesionales como los terapeutas ocupacionales cuya responsabilidad abarca los diferentes aspectos del desempeño cotidiano frente a poblaciones que están expuestas de manera permanente a la perdida de calidad de vida cotidiana, qué ocurre con la población colombiana sometida a toda clase de atropellos, donde la constante es la violencia y el miedo, cuando cada día hay miles de desplazados que pierden sus referentes cotidianos e históricos?

Para conservar la lógica del discurso vuelvo al centro de la intervención en los modelos amplios de participación y me encuentro que el foco de atención es la familia, que está situada en el límite entre lo público y lo privado, es decir que las consecuencias de su funcionamiento repercuten y son reguladas en instancias públicas. Según un informe reciente de Haz Paz, la alta prevalencia de violencia intrafamiliar en Colombia indica que es un problema de salud pública, con implicaciones serias para la salud física y mental de las mujeres, los hombres y los niños.

La alta prevalencia y gravedad de la violencia intrafamiliar queda demostrada por las consecuencias en la salud física y emocional de quienes la experimentan. Dentro de los efectos fatales se encuentran el riesgo de homicidio, suicidio o mortalidad materna y en los no fatales pero de gran impacto y larga duración, se encuentran los ocurridos en la salud mental que involucran depresión, ansiedad, problemas sexuales, insomnio y desórdenes relacionados con la experiencia traumática (Forensis, 1999) No tengo a mano datos referentes al desplazamiento pero la situación no es mas halagadora cuando poblaciones enteras pierden sus raíces y su cultura cotidiana, sus principios y los lazos que hacen significativa su existencia, me parece que todas estas situaciones atañen a la Terapia Ocupacional. 
En Colombia, cuando la vida ha perdido sentido, no podemos los terapeutas pensar en soluciones exclusivamente personales, en lo personal están involucradas también las huellas de los social.

Hemos perdido la dimensión de lo que significan vida cotidiana su relación con y discapacidad? No podemos olvidar que tanto la ocupación como la situación de discapacidad se relacionan con toda la población, los invito, a los terapeutas que están aquí congregados à que pensemos si como grupo profesional, como comunidad académica organizada debemos asumir una posición y manifestarnos frente a la grave situación del país y cómo lograr que esos procesos realmente tengan impacto y afecten todo nuestro comportamiento profesional .

\section{Bibliografía}

Caicedo, María Eugenia. Currículo integrado para una educación integral. Ponencia XII Congreso Nacional de T.O. Marzo 2001. Sin publicar.

Consejería Presidencial para Política Social. Metodología para la formación de política pública en el área social. Versión prueba territorial. Sin publicar. 2001.

Francisco, B. Terapia Ocupacional. Papirus Editora, Campinas. 2001.

Instituto dé Medicina Legal Forensis datos para la vida. 1999.

Keilhofner, G. Conceptual Fundations of OT, 1997.

Vergara, Carmen H. Gestión en el desempeño profesional de T.O. Ponencia XII Congreșo Nacional de T.O. Marzo, 2001: Sin publicar.

Willard/Spackman. Terapia Ocupacional. 1998.

Trujillo y otros. "Más allá de una visión clínica de la discapacidad". En Ocupación Humana. Vol: $8, \mathrm{~N}^{\circ} 4$ de 2000. 